Please do not remove this page

RMIT

UNIVERSITY

\title{
The digitization of Pacific cultural collections: Consulting with Pacific diasporic communities and museum experts
}

Singh, Supriya; Blake, Meredith

https://researchrepository.rmit.edu.au/esploro/outputs/9921858344101341/filesAndLinks?institution=61RMIT_INST\&index=null

Singh, S., \& Blake, M. (2012). The digitization of Pacific cultural collections: Consulting with Pacific diasporic communities and museum experts. Curator: The Museum Journal, 55(1), 95-105.

https://researchrepository.rmit.edu.au/discovery/fulldisplay/alma9921858344101341/61RMIT_INST:Resea rchRepository

Document Version: Submitted Version

Repository homepage: https://researchrepository.rmit.edu.au

(C) 2012 The California Academy of Sciences

Downloaded On 2023/04/26 17:15:24 +1000 
Singh, S and Blake, M 2012, 'The Digitization of Pacific Cultural Collections: Consulting with Pacific Diasporic Communities and Museum Experts', Curator the Museum Journal, vol. 55, no. 1, pp. 95-105.

\title{
The digitization of Pacific cultural collections: Consulting with Pacific diasporic communities and museum experts
}

\author{
Supriya Singh and Meredith Blake
}

Prof Supriya Singh

Professor, Sociology of Communications

Graduate School of Business and Law/ Smart Services Cooperative Research Centre

RMIT University

GPO Box 2476

Melbourne VIC 3001

Australia

supriya.singh@rmit.edu.au

Tel: 61399251327

Meredith Blake

Research Fellow

Graduate School of Business and Law/ Smart Services Cooperative Research Centre RMIT University

GPO Box 2476

Melbourne VIC 3001

Australia

meredith.blake@rmit.edu.au

Tel: 61399251576 


\title{
Responsible digitization of Pacific cultural collections: Consulting with Pacific diasporic communities and museum experts ${ }^{1}$
}

Abstract

\begin{abstract}
Reservations around digitization of cultural collections revolve around the digital push for universal access and scalability. This universal push can infringe the different levels of access often required by Indigenous communities, particularly for secret and/or sacred cultural objects. There needs to be consultation before digitization in order to ensure that digitization delivers the promised benefits of broadened access while respecting traditional knowledge and copyright. Culturally sensitive consultation needs to include source communities, diasporic populations, museum and cultural experts. It is only then that the Web can potentially revitalize culture, harness the power of the visual, and connect cultural objects to stories of every-day and ceremonial use and meanings. The paper is based on open-ended interviews in Australia with 27 people from the Pacific diaspora and 17 museum experts and specialists on Pacific cultures. It brings the voices of the Pacific into the discussion of digitization of their cultural collections.
\end{abstract}

\section{Introduction}

Museums across the world, including those with significant Pacific cultural collections, are moving towards digitizing their collections, using the Internet and social media. The extent of digitization varies from having catalogue type entries to images associated with video stories relating to objects; allowing for user generated content; or/and being a fully searchable Web-based resource; and enabling communication via social media. Digitization allows museums to make accessible a greater part of their collections, than is physically feasible. As Shahani et al. (Shahani, Nikonanou, and Economou 2008) say the use of social media particularly allows users to 'actively engage and influence the organization, creation, and sharing of online content' (p.57).

Indigenous populations also see digitization as a way of revitalizing their culture, projecting their own voice, connecting across generations and with other Indigenous groups. (Verran and Christie 2007; Srinivasan 2006; Ginsburg 2007; Srinivasan et al. 2009). The conflict and concerns arise over access, costs of digitization and the curatorial voice.

The first concern is with digital media enabling information to become universally available, without central control. In indigenous cultures, however, access to some cultural objects, particularly secret and/or sacred objects, is granted to people based on their gender, age, clan status and/or initiation. Making these objects universally accessible goes against their traditional knowledge and copyright. As Verran and Christie (2007) note:

\footnotetext{
...a significant number of indigenous and nonindigenous people respond with horror to the idea of using digital technologies in indigenous knowledge practices. Many people feel that computers and other digital tools will do more harm than good. Many people are concerned about disenfranchising Aboriginal knowledge authorities, further marginalizing legitimate Aboriginal interests, diverting energy and resources from Aboriginal priorities, backgrounding Aboriginal sensibilities and sensitivities about valid knowledge practices, and misappropriating intellectual property. In short, there is a widespread suspicion that digital technologies can only work by treating the knowledge of indigenous Australians as a commodity (p. 215).
}

\footnotetext{
${ }^{1}$ An earlier version of this paper was presented at 'Casting the Net Symposium': A joint Smart Services CRC/ RMIT/Australia Museum forum exploring issues of intellectual property, traditional knowledge in digital cultural collections. Australian Museum, Sydney, $17^{\text {th }}$ September 2010
} 
Hughes and Dallwitz (Hughes and Dallwitz 2007) speaking of the Anangu, a remote Indigenous Australian community, point out that a breach of security and access rules 'would be a breach of traditional Anangu law. This would incur the threat of prescribed punishments that, in very serious cases, can include the threat of personal physical injury, illness or damage to property.' (p.153). They say that

Any IT strategy dealing with cultural material must avoid any perception of technological colonisation and loss of local ownership. This point is worth stressing, as this single cultural difference between standard IT practice and indigenous sensibilities is the primary risk to the success of IT projects with indigenous Australians (p156).

The second concern is with the costs of digitization. The IT community sees digitization as a cost effective way of broadening access. However, culturally sensitive consultation before digitization is costly and can take a long time. This consultation is particularly important for it is only through a sustained relationship that museum officials can understand the restrictions, as at times it is prohibited to speak of the access restrictions. Moreover any attempt to try and combine different cultural collections in one data base are also fraught, for different Indigenous communities see themselves as culturally distinct Nations (Hughes and Dallwitz 2007). As Hughes and Dallwitz say, 'Any attempt to combine different groups' culturally specific information in one repository would meet serious resistance’ (p. 156).

Museums have put in place extensive protocols and practices for consultation with Indigenous and Pacific peoples relating to the collections (Christidis et al. 2008)). In some Indigenous communities, digitization has also been accompanied by consultation with source communities (Srinivasan et al. 2009). What this shows is that consultation has to precede attempts to digitise cultural collections.

The third conflict is that digitization enables user-generated content, bringing into question the balance between curatorial expertise, the value of 'crowdsourcing' and democratizing access (Proctor 2010). The issue is also again one of control and access. As Hughes and Dallwitz say if we consider indigenous experience of White Australia,

\footnotetext{
...it is understandable why any strategy that has the ultimate aim of centralising information would meet with strong resistance from indigenous Australians. In the development of the software for Ara Irititja, we have been constantly reminded of the concern of indigenous peoples that the final result will not reduce protection, control, rights over and local ownership of their cultural material. The concern is whether the new technology is going to open their culture to more abuse and misappropriation of the kind historically suffered by most Australian indigenous peoples (p. 156).
}

In this paper we draw on our qualitative study to present what the Pacific diasporic population, museum and cultural experts in Australia would like to see in terms of access, consultation and the curatorial voice relating to the digitization of Pacific collections on the Internet. The voices from the Pacific diaspora bring a new perspective to the policy and academic discussions of digitization of Pacific cultural collections.

\section{Our study}

This qualitative study was conducted by RMIT researchers who are part of the Smart Services Cooperative Research Centre (CRC). ${ }^{2}$ Within the CRC we worked collaboratively with the Australian Museum in Sydney, which holds 60,000 objects in its Pacific collection. At present, the Australian Museum does not have a permanent exhibition of its Pacific collection. Like all major collecting institutions, the Museum has a small proportion of its Pacific collection accessible through loans for exhibition purposes, and limited behind the scene visits by members of creator 
and diasporic communities, researchers and the general public. The Australian Museum together with the University of Wollongong has piloted digitization of 427 cultural objects in the Virtual Museum of the Pacific (http://epoc.cs.uow.edu.au/vmp/\#).

Our study is based on open-ended individual and group interviews with 44 people -27 who identify themselves as being from the Pacific diaspora in Australia and 17 museum and cultural experts on the Pacific. Four of the museum/cultural experts were themselves of Pacific Islander heritage. Two of the diasporic members were the Anglo-Australian spouses of Pacific Islanders.

In our convenience sample, we have wide representation from the diasporic population from the Pacific in Melbourne, Sydney and Brisbane. We also covered important experts and museum specialists in Australia connected to the Pacific collections, ensuring that we spoke with those who were known to have positive and negative views on digitization. All participants were given the choice of anonymity and confidentiality. Those who chose to be identified by their own names had an opportunity to review the draft paper to ensure they had been accurately quoted and in context.

The interviews were transcribed and analyzed using NVivo 8, a computer program for the analysis of qualitative data. This process of analysis helped display in a transparent way how we arrived from the interview data to best practice guidelines.

\title{
Responsible Digitization
}

Most of the diasporic community and the museum experts and specialists we interviewed favour the responsible digitization of Pacific cultural collections. Museums today are obliged to digitize, as the Internet is an important communication channel. As Joses Kenneth, 35-44 years old, a Ni-Vanuatu IT professional says, '... we live in an age where we don't really have...a choice'.

Professor Amareswar Galla who has a long involvement with the Pacific and cultural collections, says,

I'm a strong advocate of using digital technologies in an appropriate way... The only thing people are asking is, when you're doing it, negotiate the appropriate way of digitizing...I support it, but I think responsible digitization is really important and that's what I advocate.

Lillian (pseudonym) a Papua New Guinean curator of a Pacific collection says,

\begin{abstract}
It's a shame not to access these collections because people need to connect with them, especially those of us here....We're away from home...That's your connection to your homeland...

Personally, I think digitization is a good thing to have, provided proper consultation and selection [takes place] of what you put out there and how much you put out there, with the community or the people that these things originate from.
\end{abstract}

Of the 44 participants, four from the diasporic community and one cultural expert are explicitly against digitization. Their main concerns are that it will not be done in a 'responsible' manner, that there will be loss of copyright, and disrespect for traditional knowledge. They are concerned that digitization is seen as an easy way of displaying the whole collection. This universal access to everything in the collection would impose Western views on Pacific notions of the secret and sacred and become a form of re-colonization.

The other 39 interview participants expressed their support for responsible digitization. Some were passionate about the broadened access. 'Thank God, somebody has finally made it accessible for us, after all these years of (using) our IP (intellectual property)', Shigeyuki Kihara, 25-34 year old Samoan/Japanese artist says. Eddie (pseudonym), 35-44 from the Solomon Islands and working in media is even more enthusiastic, saying, 'I can only see positive there. I don't know much about intellectual property rights....but ... from a layman’s point of view, I think it’s a bloody good idea.'

There is little doubt from our interviews that the diasporic community thinks they would benefit from digitization. It is a connection with their heritage. Digitization raises awareness that museums and galleries in Australia have substantial Pacific collections, something that many of our diasporic participants did not know. 'Alopi Latukefu, 35-44 of Tongan, Polynesian and Melanesian descent 
who has written on IT issues in remote Aboriginal communities says having the collections digitized will become increasingly important as future generations in the diaspora get further away from their traditions.

'Alopi says,

It will be a generation or two before young people of Tongan or Melanesian descent, or others, who live in other places start to say, 'Well, I actually don't understand that much about the culture I come from and how can I understand a bit more and what access do I have?' Those questions aren't yet there because Pacific communities, as they are, are incredibly, highly integrated under the family model and so there still exist strong links ... to the culture we come from.

The diasporic population and the experts also noted that the Web is an oral and visual medium. It allows the opportunity of sharing stories, of presenting the linkages between material culture, stories and everyday practices. Karlo (pseudonym), 55-64, a Tongan elder in Australia notes,

One thing that I know of the Tongans, maybe it's the same with other Islanders - they like to 'read' pictures.... I think they will be excited about it because they are a communal society... It's being shared, which is really one of the bases of a communal society: you share things...

Museum curators are amongst the most enthusiastic about digitization, for it allows them to place material culture in the context of people's everyday lives, ceremonies, memories and beliefs. Imelda Miller, Assistant Curator of Torres Strait Islander and Pacific Indigenous Studies at the Queensland Museum says that with digitization

You can make relationships with other places in the Pacific, with other Pacific museums or other indigenous museums across the world. You're able to make that kind of connection to stories to show that there's strength in what we're saying, looking at the spiritual relationships and how true that is, and it exists around the world. Online you can show that; you can link those things, whereas here in a museum you might not be able to.

Dr Barry Craig, Senior Researcher with the Foreign Ethnology department of the South Australian Museum says digitization allows the museums to make their collections useful for a variety of audiences. He asks, 'If you are storing these things what are you storing them for? ... If you are going to keep it, do something useful with it'.

Their support was based on a number of qualifications. Frequent reservations were stated such as the need for museums to consult communities before objects of sensitive, ritual or sacred significance were considered for digitization. The risk of photographs of objects being downloaded by internet users inappropriately was also commonly cited in interviews, as was the fear that tangible designs or intangible components of heritage (traditional knowledge, songs and rituals) could be copied by other people who had no right to know or practice that culture.

Participants grappled with the tension between 'access' and 'control'. Although they explicitly expressed reservations associated with 'loss of control' they generally weighed up these arguments against the current situation of limited 'access' to Pacific collections held by foreign museums. On balance the remaining 39 participants welcomed digitization as one way of broadening access.

Physical access, photographs, traveling exhibitions continued to be important for the experience of the Pacific cultural collections. Digitization was not a substitute for physical access. Joycelin Kauc Leahy a Papua New Guinean, freelance curator and Managing Director of Beyond Pacific Art, says that at present Australian museums give little physical access to their Pacific collections. A person has to get in touch with the Museum, hoping they will be able to open up their vaults. Once she did get access, she was awed by the scale and content of the collections. She says some of

....the things I have never seen myself as a child ...growing up in my village in Papua New Guinea. So, I feel that they're vital heritage. ...They're even...national heritage, that [is] totally inaccessible to any generation; even the generation before me... They're not shown publicly.

She says in one museum she saw things she had not seen in the national museum in Papua New Guinea. 'So to me that's a ...massive loss to the generation or generations.....My children should have the right to see.' 


\section{Restricting Access to Secret and sacred objects}

Secret and/or sacred cultural collections have to be treated with particular care, as often physical access to them is restricted. Even when the object is not secret, the rituals around it may not be shared between men and women, the initiated and the uninitiated within the tribe, or across tribes.

Edward, (pseudonym), a cultural expert of the Pacific says

There are certain things that women are not allowed to see. There are certain things that men may not be allowed to see...Also, there are certain things that can only be seen ... from a distance and they may only be allowed to see one side of it...A lot of the headdresses and masks, you're not allowed to see inside.... Unless you have the rights,...you can be fined. If you repeatedly infringe that copyright system and you don't pay the fines, you can be killed. And that still goes on now, today.

Edward (pseudonym) worries that digitization will not respect Pacific cultures. He adds,

It's almost like stripping yourself fully naked and exposing yourself, because of the nature of secrecy and levels of knowledge and access to knowledge and access to what you see, hear and do, learn, in Melanesian culture....With Melanesian cultures you have to be very highly selective, what you put online, how you put them online, and what information you put on with them.

Other experts and people from the diaspora agree with the need to show respect. They speak of the need to consult in grey areas. Jason Gibson says much of the ceremonial material in the Spencer and Gillen Collection is clearly restricted and cannot be shown publicly. He says,

But there is some grey area and there's been .... long history of consultation with community about that portion of the collection. Until access levels are determined the project will group this material together within the classification 'yet to be determined'. This material would then feature in future discussions with senior custodians. The access levels may change over time and will change according to contexts as well....We just have to work within the ...cultural context of the time

For Evelyn Baines, 45-54, a Solomon Islander, the feeling of the sacred is palpable in some objects. She speaks of how the British Museum had invited her to check some of the objects in their Santa Isabel collection, and she said there was one object in particular where she felt if she touched it, 'it might do some harm to us'. Two fellow visitors from the Western Solomons had similar feelings about this particular object. So, they felt 'we should show high respect to all this because our ancestors did have high respect for these objects.'

Among the persons we interviewed from the Pacific diaspora in Australia, there is little uniformity about the cultural objects that are secret and sacred. People from the diaspora and other experts point to the immense cultural diversity in the Pacific and the need to take into account changing ideas of the secret and sacred. Evelyn Baines says, 'The older people want to share these cultural objects so that the younger people can know their culture'. Personally, she says, she would display them in a museum,

...because I'd like the younger generation to know about how my people used to be, how they respect these things... as long as they also want to respect all these collections of old items. For me, it's so important that this knowledge is handed down to the younger generation.

Many of our participants from the diaspora could not think of anything that was secret or sacred and should not be digitized. This was particularly true for those from Fiji, Samoa, Tonga and Solomon Islands, who had long been exposed to Christianity. Tevita (pseudonym), 55-64 from Fiji who works in language studies, said, ‘...for Fijians the taboos that are associated with certain traditional objects have I suppose generally been lost or set aside because of the Christian beliefs and practices...'

Seini (pseudonym) 35-44 a Tongan artist also said,

Tonga really doesn't have that kind of taboo because they have totally accepted religion and accepted that those kinds of objects are just objects. They are not associated with anything except possibly traditional kava ceremonies. 
Grace (pseudonym) a 35-44, nurse from the Solomon Islands knows of places that are taboo, but no taboo objects. Robert Anita, 25-34, a teacher and a Solomon Islander says, 'I think in my culture all human remains should be kept secretly in a house that belongs to the spirits'.

\title{
Respecting copyright and traditional knowledge
}

Some of our participants expressed reservations about digitization because it would lead to an infringement of copyright and traditional knowledge. Having the image of the object online would lead to others copying traditional designs and imported products being passed off as authentic craft. Non-Indigenous artists would imitate Indigenous art.

Samuel (pseudonym) 65+ from Papua New Guinea relates a story that encapsulates both his support for digitization, and his concern about the possibility of images being used and copied.

I see benefits of it. I mean, it [provides access] in the same way as in a museum, but the thing that I feel uncomfortable about online is that nowadays things are copied and then... replicas of the thing are made and copied. I think that sort of degrades what it is or removes any sacredness of what it is. .... It's my experience in Papua New Guinea that ... China, has copied certain images, like a Tubuan image. In fact, my father commented to me once when he saw an image on a lap-lap [sarong], where they separated the [the body from] the headdress... He said to me "You know, they have ruined our culture by doing that”.

Others were not worried as it is the knowledge relating to making the cultural object that is secret and copyright, rather than the object itself. Dr Michael Gunn says that on the Tabar Islands copyright does not rest in the object, which is often destroyed, but in the reproduction of the object. He says people in New Ireland told him that

\begin{abstract}
...when we Westerners buy an object, we're not buying a copyright. We're just buying a piece of carved wood. The copyrights are the rights that are used to reproduce that object, to recreate it in its proper context. In New Ireland, this copyright is specific to a particular group and clan. Though it is supposed to go down the matrilineal line, it often goes from father to son. Moreover copyright moves. What was owned by one group 80 years ago, they may have sold the copyright on.... Whoever last owned the copyright when that piece was produced, they may have produced it and then moved the copyright on and they don't own it any more...
\end{abstract}

During interviews there was a lot of discussion about issues surrounding traditional knowledge and control. Dr Ron Vanderwal, Curator Emeritus, Anthropology at Museum Victoria says:

\begin{abstract}
I've always been a proponent of getting stuff up there. It's kind of this great divide between collections managers and curatorial staff. [Collection managers' concerns are] that it becomes public information and probably the worst of that, in their eyes, is that there are a number of objects which are images and images can be used in publications in which we, the museum, have no control over. Mind you, even ones that we have supplied to other people, we have no control over once they leave in the form of digital images.
\end{abstract}

Joses Kenneth, 35-44 a Ni-Vanuatu IT professional says that the issue is not whether the museum loses control of an image. The person who loses control is the one who owns the artefact. He says, 'The Ni-Vans have already lost control of it by whoever got it from Vanuatu, whether it's secretive or whatever'. However, in Vanuatu the traditional way of passing down the knowledge is protected, whether it's on the web or it's not. 'The Chinese might try and imitate it, but I don't think they'll ever achieve that way of making it. So, the traditional method and secrecy will be protected regardless.'

Karlo (pseudonym), 55-64, a Tongan elder in Australia notes, 'If there's something that is here in the museum that shouldn't be on the Net, then it shouldn't be here in Australia anyway.'

\section{Consultation}

Consultation is essential in resolving issues of access, digitized or physical, to parts of the cultural collections that may infringe on the secret, sacred, copyright and traditional knowledge. The experts 
we interviewed pointed out that there are protocols and ethics of consultation with Pacific Islanders, Maori, Australian Indigenous groups, Indigenous people in the United States and Canada have been discussed (Pacific Islands Museums Association 2006; New Zealand Ministry of Pacific Affairs undated; Museums Australia Inc. 2005; Te Papa National Services Te Paerangi 2006; Aboriginal and Torres Strait Islander Library and Information Resources Network 1995; Australian Heritage Commission 2002; US Public Law 101-601 1990; Task Force on Museums and First Peoples 1992). Agreement has been reached with museums around the world on the need for consultation with Indigenous peoples regarding their cultural heritage (Sullivan et al. 2000, Sullivan et al. 2003).

We identified three major principles that were universally acknowledged in the policy documents relating to consultation. Firstly, indigenous people are the primary stakeholders that hold knowledge about and can make decisions about their cultural heritage. Secondly, museums should move beyond what the law requires them to do and be guided by ethical principles in their consultations. The Aboriginal and Torres Strait Islander Library and Information Resources Network (Aboriginal and Torres Strait Islander Library and Information Resources Network 1995) quote Peter Anderson to say 'the law as it stands is simply not a sensitive enough instrument to deal effectively with the management of spiritually significant material' (cited on pp 4-5). The New Zealand Ministry of Pacific Affairs Pacific Consultation Guidelines (New Zealand Ministry of Pacific Affairs undated) state:

Consultation is an ethical process... Consultation is much more than participation...Consultation involves serious ongoing obligations to the people consulted. It is a process done in utmost good faith, not to be undertaken for the sake of it (p. 1)

And thirdly, museums should conduct all consultation, respecting cultural uniqueness. As the PIMA Code of Ethics (Pacific Islands Museums Association 2006) states 'Pacific museums build and maintain relationships of cultural understanding and mutual respect with the communities they serve' (p.1).

There is no dispute about these principles underlying consultation. Some cultural institutions have gone further to give practical advice to museum professional on how to put these consultation principles into practice (Crayford and Wraight 2005; Museums Australia Inc. (QLD) 1998). These include culturally distinctive communication protocols, respect for hierarchy and ways of showing respect.

Our interviews with museum curators give real life instances of the difficulties of consultation. Ideally, consultation should precede digitization. In practice, though, all the curators we interviewed say they are dissatisfied with the time and resources available for consultation.

Some of the best results have been achieved by working with cultural experts from the Pacific Islands in Australia. Ana (pseudonym), 25-34 a Papua New Guinean in media in Australia recommends a sure route for avoiding disputes over access and respect. She says,

They'll be able to talk you through the protocol and give you a much better and deeper understanding of the artwork if you work with them. They'll show you the way.

Sana Balai stresses that even as a Melanesian, she herself does not always feel confident working with Pacific artefacts:

Being a Melanesian as I am does not necessarily make it easy to work with or present artworks from Melanesia. The reason is that nearly all sculptural artefacts and art forms held in museums and galleries are made by men and therefore can only be handled or presented by men or someone from the culture from which the artworks originate. I am a female working in a male dominated culture here and I am constantly debating with myself because of this issue. I often have to remind myself that it is all right for me to work with these artworks. I say to myself, 'You are the right person to work with these materials because you are culturally linked to them' (Presentation at 'Casting the Net Symposium', Sydney, 17 September 2010).

Eight of the 44 participants suggest liaising with the Pacific Islands Museums Association (PIMA) and/or the Pacific museums themselves. This would facilitate the sharing of research about Pacific 
material culture. It would introduce foreign museums to appropriate source communities to discuss specific or categories of objects which were appropriate for digitization.

Our interviews show it is preferable to go to the source communities and follow the path they suggest for consultation. Many of our diasporic participants say they do not have the specialist knowledge needed to accurately describe which objects should or should not be digitized. They are conscious of the immense cultural diversity even in their own region and so do not feel they could speak for more than their own cultural group. Melanesian interview participants in particular, continually cite the number of language groups within their country as evidence of cultural diversity and the fact that they could really only know about their community ${ }^{3}$.

Jane (pseudonym) who works with a Pacific collection in a state museum and is herself of Pacific Islander descent agrees with the need to consult members of a source community before digitizing unfamiliar cultural objects. She says:

I would feel uncomfortable to put collections online if they weren't from my place and I hadn't
spoken to anyone from that community, because that's their stuff...It belongs to the people and
without working with the community and then just putting it online for the whole world to see...it's
not very fair.

Dr Barry Craig from the South Australian Museum cautions that digitization is a time-consuming and difficult process. He recommends starting with the part of the collection where there is significant expertise in the cultural institution. There also needs to be a long history of consultation around these collections. It is then likely that digitization will be in accordance with the community's access codes and preferences.

\section{Conclusion}

From our interviews with experts and the diasporic community, we conclude that people are enthusiastic about broader access to Pacific collections. Digitization has the potential for broadening access to museum collections. However, digitization requires close consultation with the community and museums in the Pacific islands, to ensure respect for culture and traditional knowledge. In this paper we bring the voices from the Pacific to add to the policy documents and ethics codes to illuminate issues around the responsible consultation of Pacific cultural collections.

Our work suggests that the next step is to ask whether digitization empowers the varied communities served by museums. The use of digitization needs to be evaluated for these different communities, so that we can answer the question: Who benefits from the digitization of Pacific cultural collections? Digitization then has to be designed for the needs of these user groups in terms of the use of multimedia, user-generated content, the role of mediation, and social media. For all groups, there needs to be effective access to digitized collections, keeping in mind the nature and distribution of the Internet, particularly in the countries of the Pacific.

We also need to know how best to use digitized collections together with traditional ways of presenting and distributing collections, such as exhibitions, public programs and publications. Some of the most forceful advocates of digitization want digitization to attract people to the actual museum experience.

\section{Acknowledgement}

\footnotetext{
${ }^{3}$ The Ethnologue Languages of the World website lists 830 living languages spoken in Papua New Guinea, 108 living languages spoken in Vanuatu and 71 living languages spoken in the Solomon Islands.

http://www.ethnologue.com/country_index.asp?place=Pacific
} 
We wish to thank all of our interview participants who generously shared their stories and thoughts with us.

\section{References}

Aboriginal and Torres Strait Islander Library and Information Resources Network. 2011. Aboriginal and Torres Strait Islander Library and Information Resources Network Protocols Aboriginal and Torres Strait Islander Library and Information Resources Network, 1995 [cited Mar. 17, 2011 2011]. Available from http://www1.aiatsis.gov.au/atsilirn/protocols.atsilirn.asn.au/index0c51.html.

Australian Heritage Commission. 2002. Ask First: A guide to respecting Indigenous heritage places and values. Canberra: Australian Heritage Commission.

Christidis, Les, Vinod Daniel, Paul Monaghan, Yvonne Carrillo-Huffman, and Kirk Huffman. 2008. Engaging with Creator Communities: The Way

Forward for Museums. The International JOURNAL of the INCLUSIVE Museum 1 (2):1-6.

Crayford, M., and J. Wraight. 2005. Connections: Indigenous Cultures and the Australian National Maritime Museum. Sydney: Australian National Maritime Museum.

Ginsburg, Faye. 2010. Rethinking the digital age. Media anthropology network working papers. 2007 [cited 10 December 2010]. Available from http://www.mediaanthropology.net/ginsberg_digital_age.pdf

Hughes, Martin, and John Dallwitz. 2007. Ara Irititja: Towards Culturally Appropriate IT Best Practice in Remote Indigenous Australia. In Information Technology and Indigenous People, edited by L. E. Dyson, M. Hendriks and S. Grant. Hershey, PA: Idea Group Publishing

Museums Australia Inc. 2005. Continous Cultures, Ongoing Responsibilities: Principles and guidelines for Australian museums working with Aboriginal and Torres Strait Islander cultural heritage.

Museums Australia Inc. (QLD). 1998. Taking the Time: museums and galleries, cultural protocols and communities: a resource guide. Brisbane: Museums Australia Inc. (QLD),.

New Zealand Ministry of Pacific Affairs. 2010. Pacific Consultation Guidelines New Zealand Ministry of Pacific Affairs, undated [cited Aug. 28, 2010 2010]. Available from www.minpac.govt.nz/resources_pacificconsultationguidelines.pdf

Pacific Islands Museums Association. 2010. Code of Ethics for Pacific Islands Museums. Pacific Islands Museums Association, 2006 [cited Sep. 17, 2010 2010]. Available from http://pima.museum/about/code-of-ethics/

Proctor, Nancy. 2010. Digital: Museum as Platform, Curator as Champion, in the Age

of Social Media. Curator: The Museum Journal 53 (1):35-43.

Shahani, Lavina, Niki Nikonanou, and Maria Economou. 2008. Museums Opening Up to Communities Using Web 2.0: Promise or Reality? The International Journal of the Inclusive Museum 1 (4):57-65.

Srinivasan, Ramesh. 2006. Indigenous, ethnic and cultural articulations of new media. International Journal of Cultural Studies 9 (4):497-518.

Srinivasan, Ramesh, Jim Enote, Katherine M. Becvar, and Robin Boast. 2009. Critical and reflective uses of new media technologies in tribal museums. Museum Management and Curatorship 24 (2):161 - 181. 
Task Force on Museums and First Peoples. 1992. Turning the Page: Forging New Partnerships between Museums and First Peoples. Ottawa: Canadian Museums Association and Assembly of First Nations.

Te Papa National Services Te Paerangi. 2006. Mātauranga Māori and Museum Practice ed Te Papa National Services Te Paerangi. Wellington: National Museum of New Zealand, . http://www.tepapa.govt.nz/SiteCollectionDocuments/NationalServices/Resources/Matauran gaMaori.pdf (accessed Mar. 17, 2011).

US Public Law 101-601. 1990. Native American Graves and Repatriation Act [25 USC 3001 et seq.].

Verran, Helen, and Michael Christie. 2007. Using/Designing Digital Technologies of Representation in Aborginal Australian Knowledge Practices. Human Technology: An Interdisciplinary Journal on Humans in ICT Environments 3 (2):214-227. 